\title{
Isolation in cell culture of nodavirus from farmed Atlantic halibut Hippoglossus hippoglossus in Norway
}

\author{
B. H. Dannevig ${ }^{1, *}$, R. Nilsen ${ }^{1}$, I. Modahl ${ }^{1}$, M. Jankowska ${ }^{1}$, T. Taksdal ${ }^{1}$, C. McL. Press ${ }^{2}$ \\ ${ }^{1}$ National Veterinary Institute, PO Box 8156 Dep., 0033 Oslo, Norway \\ ${ }^{2}$ Department of Morphology, Genetics and Aquatic Biology, Norwegian School of Veterinary Science, PO Box 8146 , \\ 0033 Oslo, Norway
}

\begin{abstract}
Isolation in cell culture of nodavirus from Atlantic halibut Hippoglossus hippoglossus suffering from viral encephalopathy and retinopathy (VER) is described. The cell line SSN-1 was inoculated with tissue material from affected juveniles ( $60 \mathrm{~d}$ after first feeding). Extensive cytopathic effects (CPE) developed approximately $5 \mathrm{~d}$ after inoculation, and were also observed after several passages in the same cell line. Cells from infected cultures showed reactivity with an antiserum against sea bass Dicentrarchus labrax nodavirus in an indirect immunofluorescence test. Analysis of infected cells with reverse transcriptase-polymerase chain reaction (RT-PCR) resulted in a product of the predicted size using primers specific for striped jack Pseudocaranx dentex nodavirus. Electron micrographs of infected SSN-1 cells demonstrated virus particles that were approximately less than $30 \mathrm{~nm}$. Challenge of Atlantic halibut larvae (4 d post-hatching) with supernatants from infected SSN-1 cells resulted in development of VER as verified by immunohistochemistry performed on larvae sampled from Day 9 after challenge. The present results show that a nodavirus from Atlantic halibut has been isolated using the SSN-1 cell line and that virus propagated in cell culture retained virulence.
\end{abstract}

KEY WORDS: Nodavirus - Viral encephalopathy and retinopathy $\cdot$ Viral nervous necrosis $\cdot$ Cell culture isolation · Atlantic halibut

\section{INTRODUCTION}

Viral encephalopathy and retinopathy (VER) (alternative term: viral nervous necrosis, VNN, according to Office International des Epizooties 1995) has been a major problem for the production of marine fish worldwide during the last decade. The first identification of the causative virus as a member of the family Nodaviridae was achieved by investigating the nucleic acids and structural proteins of purified virus from striped jack Pseudocaranx dentex larvae with nervous necrosis (Mori et al. 1992). The nodaviruses are small (25 to $30 \mathrm{~nm}$ ), non-enveloped icosahedral viruses with a

*E-mail: birgit.dannevig.@vetinst.no genome consisting of 2 single stranded RNAs. Piscine nodaviruses have been shown to infect a variety of marine species, especially at the larval and juvenile stages, and the infection usually results in high mortality (reviewed by Munday \& Nakai 1997).

In Norway, outbreaks of VER were first recognized in farmed Atlantic halibut Hippoglossus hippoglossus larvae and juveniles in 1995 (Grotmol et al. 1995, 1997a). Diseased fish showed vacuolating encephalopathy and retinopathy as well as endocardial lesions, and non-enveloped virus particles with capsid diameters of $25 \mathrm{~nm}$ were detected in brain tissue. Furthermore, nervous tissue showed reactivity with a rabbit immune serum raised against striped jack nervous necrosis virus (SJNNV) using an immunohistochemical 
technique (Grotmol et al. 1997a). The presence of nodavirus in experimentally infected yolk-sac larvae of Atlantic halibut was also detected using reverse transcriptase-polymerase chain reaction (RT-PCR) with primers specific for the SJNNV coat protein gene (Grotmol et al. 1999). These results suggest a close relationship between the Atlantic halibut and striped jack nodaviruses.

Until recently, cultivation of nodavirus from different marine fish was not possible as the most commonly available fish cell lines did not seem to permit growth of these viruses (Munday \& Nakai 1997). Frerichs et al. (1996) achieved the first successful cultivation of a piscine nodavirus using the SSN-1 cell line derived from a striped snakehead fish Ophicephalus striatus. This investigation reported the isolation of nodavirus from diseased sea bass Dicentrarchus labrax. Recently, the susceptibility of the SSN-1 cell line for nodaviruses from various marine species has been studied, including nodavirus from Atlantic halibut (strain AHNor96 from Norway) (Iwamoto et al. 1999). No cytopathic effects (CPE) were observed in SSN-1 cell cultures following inoculation with the AHNor96 virus strain, and intracellular virus particles were not detected. However, staining of infected cells using an immunofluorescence technique suggested viral growth.

In the present report, we describe the isolation of a nodavirus from farmed Atlantic halibut in the SSN-1 cell line. Infected cultures developed extensive CPE, and intracellular virus particles with the appropriate morphology and size were detected. In addition, challenge experiments with virus propagated in cell culture showed that the virus retained virulence after several passages in cell culture.

\section{MATERIALS AND METHODS}

Field samples. Atlantic halibut juveniles from a Norwegian fish farm were collected during a disease outbreak in July 1998. At sampling, the mortality was approximately $10 \% \mathrm{~d}^{-1}$ and finally reached $99 \%$. The fish measured 1.2 to $1.4 \mathrm{~cm}$ in length and were sampled approximately $60 \mathrm{~d}$ after first feeding. Water temperature was $12.5^{\circ} \mathrm{C}$ and the salinity was $33 \%$. Moribund fish were killed and fixed in $10 \%$ phosphate-buffered formalin and transported to the laboratory. For virological examinations, 9 fish were transported alive in seawater. Upon arrival at the laboratory, the head regions from 3 fish were pooled and transport medium (Eagle's minimal essential medium, EMEM, pH 7.6, supplemented with $4 \mathrm{mM}$ L-glutamine, $16.4 \mathrm{mM}$ Tris-buffer, $100 \mu \mathrm{g} \mathrm{ml}^{-1}$ gentamicin, and $10 \%$ newborn bovine serum) was added before storage at $-80^{\circ} \mathrm{C}$ until further preparation.
Histology and immunohistochemistry: Formalinfixed specimens were processed for light microscopy according to standard methods. Sections (4 to $6 \mu \mathrm{m}$ ) were stained with haematoxylin and eosin (H\&E).

Immunohistochemical examination of the field samples was performed as described by Grotmol et al. (1997a), with minor modifications. Briefly, after deparaffination of the sections of the whole fish, $5 \%$ bovine serum albumin (BSA) in Tris-buffered saline (TBS, pH 7.4) was added to block non-specific antibody binding sites. Then, rabbit antiserum against SJNNV, kindly provided by Dr T. Nakai, University of Hiroshima, Japan, was applied in dilution 1:1500 in $2.5 \%$ BSA in TBS. The sections were then rinsed with TBS before the secondary antibody, biotinylated goat anti-rabbit IgG (Dako, Glostrup, Denmark) diluted 1:500, was added. After further rinsing, streptavidin alkaline phosphatase complex (Amersham International, Buckinghamshire, UK) was applied. Following another rinsing, the alkaline phosphatase reactivity was detected by adding Fast Red chromogen (Sigma Chemical Co., St. Louis, MO, USA), followed by washing and counter-staining with Mayer's haematoxylin.

Immunohistochemical examination of the larvae from the virulence studies was carried out as described above, except that the rabbit antiserum against SJNNV was replaced by a rabbit antiserum (diluted 1:3000) against a recombinant coat protein of the SJNNV (Grotmol et al. 1999), which was kindly provided by Dr Eirik Biering, Intervet Norbio A/S, Bergen, Norway. This antiserum was not available at the time for use in the diagnosis of field samples.

Virological examination: The samples of the head regions were homogenized in transport medium by grinding the tissue with a glass pestle. The homogenates $(10 \%$, w/v) were centrifuged $(4000 \times g, 15 \mathrm{~min}$ at $4^{\circ} \mathrm{C}$ ) and the resulting supernatants passed through $0.22 \mu \mathrm{m}$ filters before inoculation on cell cultures. Since infectious pancreatic necrosis virus (IPNV) is ubiquitous in the Norwegian fish farms and the Atlantic halibut is suceptible to IPNV (Biering et al. 1994), the samples were also examined for the presence of this virus.

Examination for IPNV: Blue gill fibroblast cells (BF-2) and epithelioma papillosum cells (EPC) were grown to $70-80 \%$ confluency in 24-well tissue culture plates using EMEM, pH 7.6, supplemented with $4 \mathrm{mM}$ L-glutamine, $16.4 \mathrm{mM}$ Tris-buffer, $50 \mu \mathrm{g} \mathrm{m} \mathrm{m}^{-1}$ gentamicin, and $10 \%$ foetal bovine serum (FBS) as growth medium (all cell culture reagents were from BioWhittaker, Wokingham, UK). The cultures were inoculated with the tissue supernatants (final tissue dilutions 1 and $0.1 \%, \mathrm{w} / \mathrm{v})$. Following incubation at $15^{\circ} \mathrm{C}$ for $1 \mathrm{wk}$, the cultures were examined by light microscopy for $\mathrm{CPE}$ before the supernatants were passed to fresh cul- 
tures of BF-2 and EPC cells, respectively. After incubation for another week, the cultures were again examined for CPE.

Examination for nodavirus: The SSN-1 cell line (Frerichs et al. 1996) obtained from The European Collection of Animal Cell Cultures (ECACC), Salisbury, UK, was grown in Leibovitz's L15-medium supplemented with $4 \mathrm{mM}$ L-glutamin, $50 \mu \mathrm{g} \mathrm{ml}^{-1}$ gentamicin and $5 \%$ FBS using $25 \mathrm{~cm}^{2}$ cell culture flasks (Falcon Primaria, Becton Dickinson Labware, Franklin Lakes, NJ, USA). The cells were grown at $25^{\circ} \mathrm{C}$. Because of the C-type retrovirus infection of the SSN-1 cell line (Frerichs et al. 1991), the cell culture work was carried out according to Bio Safety Level 2 as recommended by ECACC. The cells were subcultured approximately every $10 \mathrm{~d}$ using trypsin-versene.

SSN-1 cells grown to 60-80\% confluency (3 d after last subculture) were inoculated with the tissue material prepared as described above. After removal of the growth medium, $1 \mathrm{ml}$ of tissue supernatant diluted with serum-free L15-medium (final tissue dilution 1\%, w/v) was added to each flask. The virus was allowed to absorb for $3 \mathrm{~h}$ at $20^{\circ} \mathrm{C}$ before $4 \mathrm{ml}$ fully supplemented L15-medium was added. The cultures were thereafter incubated at $20^{\circ} \mathrm{C}$ and inspected daily for CPE. When CPE were obvious, the supernatants were passed to new cultures. In some cases, the cell cultures were frozen and thawed once to ensure a high yield of virus in the supernatant. For immunocytochemistry or RT-PCR (see below), infected cells were removed by treatment with trypsin or with a cell scraper and collected by centrifugation.

Determination of virus titre: Virus titre was determined by end-point dilution of the supernatant (10-fold serial dilution) on SSN-1 cells cultured in 96-well cell culture plates using 6 wells per dilution. The cultures were examined for CPE after $7 \mathrm{~d}$ and $50 \%$ tissue culture infective dose, $\mathrm{TCID}_{50} \mathrm{ml}^{-1}$, was determined according to Kärber (1931).

Virus identification: Immunocytochemistry: Cells from SSN-1 cultures exhibiting CPE were collected by low speed centrifugation and examined for the presence of nodavirus using an indirect immunofluorescence test. The cells were suspended in phosphatebuffered saline (PBS), pH 7.4, and applied in a small volume to wells on Teflon-coated micro slides. After drying at room temperature, the cells were fixed in $100 \%$ acetone and thereafter incubated with antiserum (diluted 1:40 in PBS) against sea bass nodavirus, strain V26, kindly provided by Dr J. Castric, CNEVA, Brest, France (Péducasse et al. 1999). This antiserum proved to be more suitable for detection of nodavirus in cell cultures than the antisera used for detection of virus in tissue by immunohistochemistry described above. Following rinsing in PBS with $0.1 \%$ Tween 20, the slides were finally incubated with fluorescein isothiocyanate (FITC)-labelled goat anti-rabbit IgG (Southern Biotechnology Associates Inc., Birmingham, AL, USA) diluted 1:50 in PBS. After drying, the preparations were mounted in $70 \%$ glycerol before examination in a microscope equipped for fluorescence.

RT-PCR: PCR amplification of the viral gene sequences of the coat protein was performed using the procedure described by Nishizawa et al. (1994). Total RNA was extracted by adding TRIzol reagent (GibcoBRL, Gaithersburg, MD, USA) to virus infected SSN-1 cultures after removal of medium. Complementary DNA was then synthesized from extracted RNA using MuLV reverse transcriptase (Gibco-BRL) and reverse primer R3 (5'-CGA GTC AAC ACG GGT GAA GA-3'). After addition of forward primer F2 (5'-CGT GTC AGT CAT GTG TCG CT-3') and Taq DNA polymerase (Gibco-BRL), the amplification cycle was repeated 30 times. The final PCR product was analyzed by agarose gel electrophoresis and visualized by ethidium bromide staining. A specific band of 430 base pairs (bp) corresponding to the predicted size was observed with successful amplification. Sequencing of the PCR product was performed by MedProbe, Oslo, Norway.

Electron microscopy: SSN-1 cells grown in $75 \mathrm{~cm}^{2}$ cell culture flasks were inoculated with diluted 4 th passage virus supernatant, corresponding to approximately $10^{4} \mathrm{TCID}_{50}$, in a volume of $3 \mathrm{ml}$ for $3 \mathrm{~h}$ before addition of $17 \mathrm{ml}$ fully supplemented L15-medium. Fixation of the cells was performed when CPE became apparent (Day 4 post-inoculation, p.i.) and when full CPE had developed (Day 11 p.i.). In the latter case, detached cells were also harvested, fixed and transferred to the corresponding sample with adherent cells. The cell layer was fixed using $2 \%$ glutaraldehyde in $0.1 \mathrm{M}$ cacodylate buffer ( $\mathrm{pH} 7.4$ ) by successively increasing the concentration of the fixative in the cell culture flask. Finally, the cells were incubated with $5 \mathrm{ml}$ fixative for 15 min. Thereafter the cell layer was carefully scraped off, and the cells from 2 parallel flasks were collected by low speed centrifugation. The resulting cell pellet was suspended in $1 \mathrm{ml}$ fixative, then washed in $0.1 \mathrm{M}$ sodium cacodylate buffer and postfixed in $2 \%$ osmium tetroxide in $0.1 \mathrm{M}$ sodium cacodylate for $1 \mathrm{~h}$. Following dehydration in a graded series of ethanol/propylene oxide and embedding in Epon, sections were stained with toluidine blue for examination with the compound microscope. Ultrathin sections were stained with uranyl acetate and lead citrate and examined in a Philips EM 208S electron microscope.

Virulence studies. Fish: Newly hatched Atlantic halibut larvae were obtained from Institute of Aquaculture, Sunndalsøra, located in an area of Norway where VER has not been diagnosed. The larvae were kept at $6^{\circ} \mathrm{C}$ in complete darkness in 6 -well cell culture 
plates (Nunc, Roskilde, Denmark). There were 3 to 5 larvae in each well, which contained $10 \mathrm{ml}$ autoclaved seawater diluted to $25 \%$ salinity with distilled water. The water was not changed during the experiment. Mortality and clinical signs were recorded 3 times per week. During periods of observation, the room was illuminated by a dim red light.

Virus preparation and challenge: SSN-1 cells were inoculated with a 4 th passage of virus supernatant. When CPE were obvious (at Day 6 p.i.), the cell cultures were frozen and thawed once. Cell debris was removed by low speed centrifugation and the resulting supernatant was used for experimental infection of the halibut larvae the same day.

Four days after hatching, the larvae were exposed to 2 different doses of virus by adding $100 \mu \mathrm{l}$ virus supernatant directly to the water $(10 \mathrm{ml})$ in each well (final doses $10^{6}$ and $10^{4} \mathrm{TCID}_{50} \mathrm{ml}^{-1}$, respectively), 120 wells per group. Parallel groups received cell culture supernatant from uninfected SSN-1 cells or were left untreated as a control. The larvae were continuously exposed to the various supernatants until sampling.
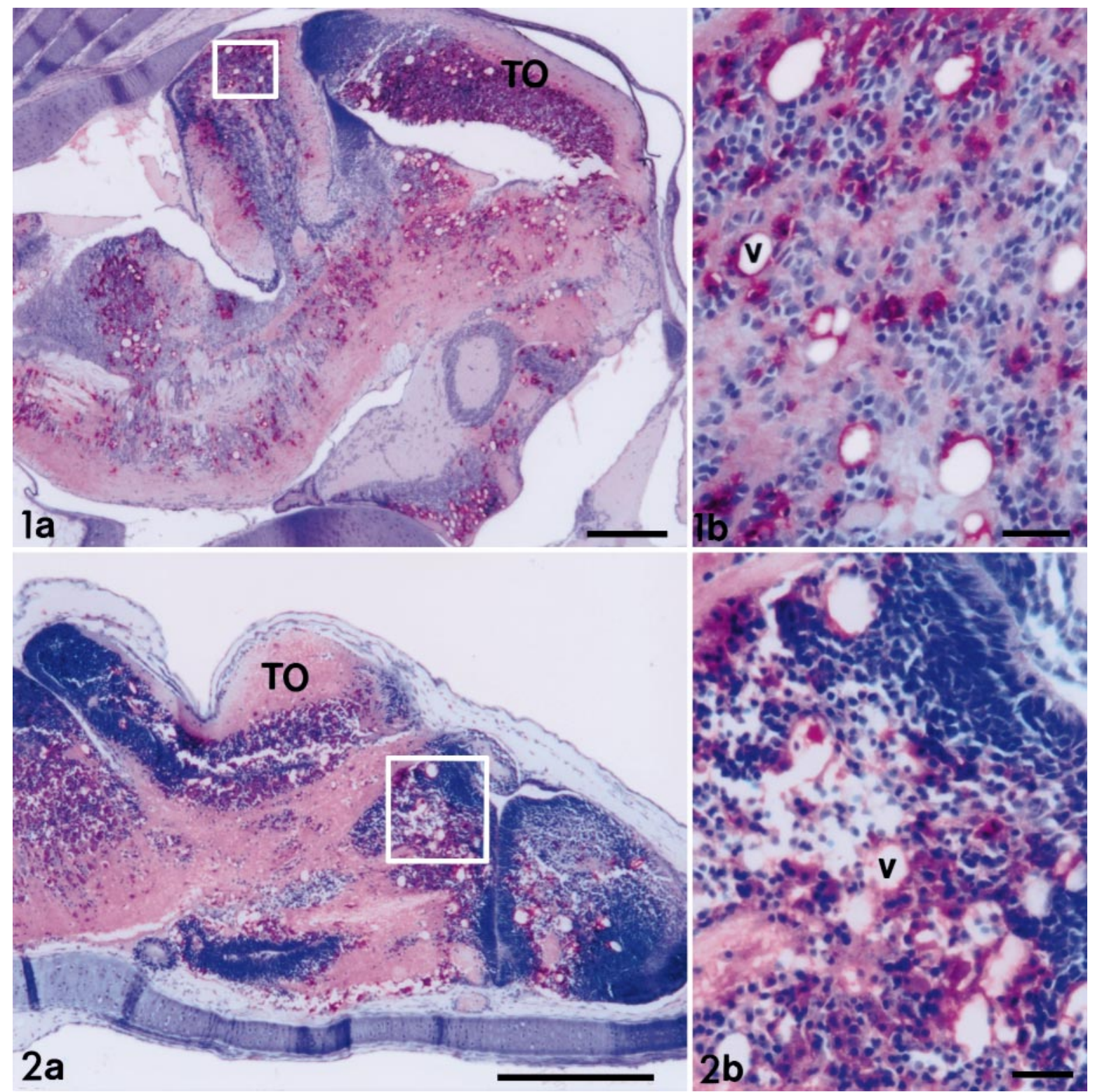

Figs. 1 \& 2. Immunohistochemical demonstration of nodavirus (red color) in Atlantic halibut. Fig. 1. Fish sampled during an outbreak of VER. (a) Reactivity was detected in all parts of the brain. TO: tectum opticum. Scale bar $=200 \mu m$. (b) Higher magnification of insert in (a) showing vacuoles (V) in the cerebellum. Scale bar $=20 \mu \mathrm{m}$. Fig. 2. Larvae sampled at Day 28 after challenge with cell culture propagated nodavirus. (a) Reactivity was detected in all parts of the brain. TO: tectum opticum. Scale bar $=200 \mu \mathrm{m}$. (b) Higher magnification of insert in (a) showing vacuoles (V). Scale bar $=20 \mu \mathrm{m}$ 
Sampling, disease diagnosis and re-isolation of virus: Three to 5 fish were collected from each group before challenge and every 2 to $3 \mathrm{~d}$ after challenge and prepared for light microscopy and immunohistochemistry, as described above.

Samples for virus isolation were collected $4 \mathrm{~h}$ after challenge as a control for passive absorption of virus to the larvae, and thereafter $13 \mathrm{~d}$ after challenge. Larvae from each group were pooled and transferred to tubes with $30 \mathrm{ml}$ sterile PBS, washed 3 times, and finally, PBS with $50 \mu \mathrm{g} \mathrm{ml}^{-1}$ gentamicin was added to a final concentration of larval tissue of $10 \%(\mathrm{w} / \mathrm{v})$. The samples were stored at $-80^{\circ} \mathrm{C}$ until use. The samples were prepared and inoculated on SSN-1 cells as described for field samples.

\section{RESULTS}

\section{Field samples}

Gross pathology, histology and immunohistochemistry

At necropsy, the gastrointestinal tract was devoid of food, but no obvious pathological lesions were recognized. Histopathological examination revealed vacuoles in the brain, medulla, spinal cord and retina. Immunohistochemical examination revealed strong reaction in cells of these tissues using an antiserum against SJNNV as the primary antibody (Fig. 1). Lesions or viral antigens were not detected in other tissues.

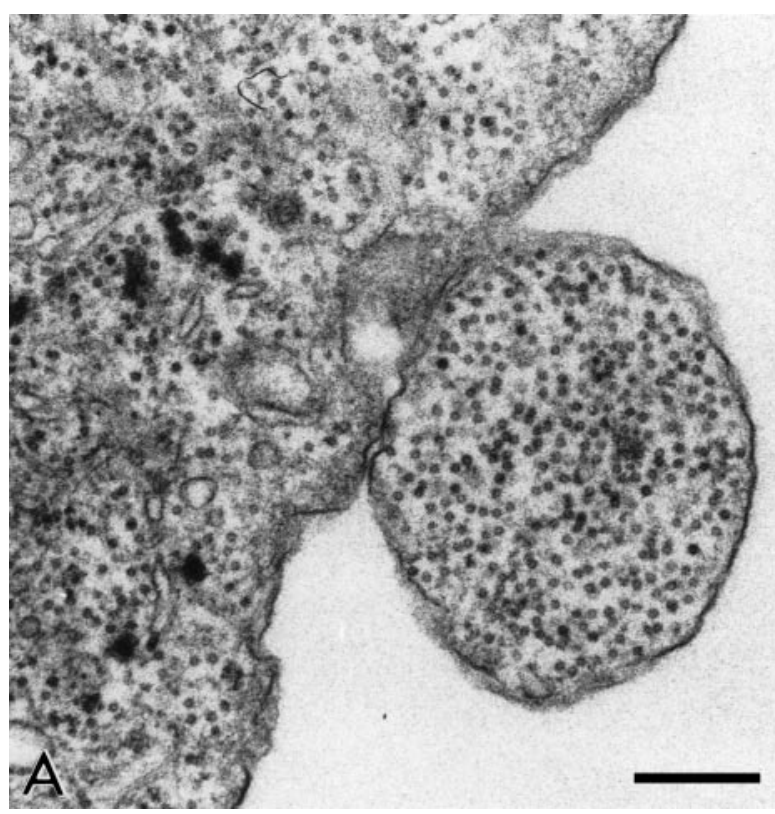

Virus isolation

$B F-2$ and EPC cell cultures: No CPE were detected in BF-2 and EPC cell cultures inoculated with the tissue supernatants from the field samples.

SSN-1 cell culture: Development of CPE was evident in cultures of SSN-1 cells 5 d after inoculation with material from 1 of the organ pools. The cells became highly vacuolated and finally detached from the growth surface. Some vacuolisation and loosened cells were also observed in control cultures, but not to the same extent as in inoculated cultures. Following serial passages of supernatants to fresh cultures, the same pattern of CPE was observed. Virus titres of approximately $10^{7}$ to $10^{8} \mathrm{TCID}_{50} \mathrm{ml}^{-1}$ were obtained after 3 passages.

SNN-1 cells harvested from the primary infected culture and from cultures of higher passages showed strong reactivity with an antiserum against sea bass nodavirus in an immunofluorescence test. Analysis of RNA extracted from infected cell cultures by RT-PCR revealed amplified DNA segments of $430 \mathrm{bp}$. The size of the PCR product is consistent with that of other fish nodaviruses using the same primer sets. The nucleotide sequence of the product demonstrated a higher degree of homology, $97 \%$, with the corresponding segment of barfin flounder Verasper moseri nodavirus (BFNNV) (Nishizawa et al. 1995) than with SJNNV (77\%). Nucleotide sequences were compared with database entries by using the BLAST search program. Intracellular, membrane bound aggregates of viral particles less than $30 \mathrm{~nm}$ were seen in electron micrographs of infected SSN-1 cells at both Days 4 and

Fig. 3. Electron micrographs of SSN-1 cells fixed $11 \mathrm{~d}$ after inoculation with cultivated virus. Aggregates of viral particles are located in membrane-bound structures (A \& B). Scale bars $=300 \mathrm{~nm}$ 
11 after inoculation (Fig. 3). The viral isolate is designated AHNV 692/9/98.

\section{Virulence studies}

Mortality

For both doses of virus, mortality was observed among larvae approximately $6 \mathrm{~d}$ after challenge and increased steadily over a 10 to $14 \mathrm{~d}$ period. Accumulated mortality reached $100 \%$ at Days 18 and 34 after challenge for the groups receiving the highest and lowest dose of virus, respectively. Some mortality was observed among control fish, but accumulated mortality was considerably lower $(40 \%$ at Day 34 after challenge) than the mortality in the challenged groups. The cause of mortality among control fish is not known, but the rearing conditions for the newly hatched larvae may not have been optimal.

\section{Histology and immunohistochemistry}

Vacuoles were present in nervous tissue of challenged fish (Fig. 2), and the lesions were similar to those observed in samples from the field disease outbreak (Fig. 1). Immunohistochemical examination revealed reactivity for nodavirus and was only detected in fish challenged with virus. Reactivity for nodavirus in cells of nervous tissue was first detected $9 \mathrm{~d}$ after challenge with the highest dose of virus and $16 \mathrm{~d}$ after challenge in the group that received the lower dose of virus. Fig. 2 shows immunohistochemical reactivity for nodavirus in nervous tissue from the high virus dose group at $28 \mathrm{~d}$ after challenge.

\section{Virus isolation}

SSN-1 cell cultures inoculated with material sampled at Day 13 after challenge developed full CPE after $4 \mathrm{~d}$ incubation. CPE were also detected in cultures inoculated with material sampled $4 \mathrm{~h}$ after challenge, but the time for appearance of CPE was delayed and developed first after $11 \mathrm{~d}$. Nodavirus was idenitifed in cell cultures exhibiting CPE using immunocytochemistry and RT-PCR. No CPE were observed in cultures inoculated with material from the control group or the group receiving supernatant from uninfected SSN-1 cell cultures.

\section{DISCUSSION}

In the present study, isolation of a nodavirus from a disease outbreak of VER in juvenile Atlantic halibut was achieved using the SSN-1 cell line. The isolated virus was identified as a fish nodavirus based on the results of immunocytochemistry, RT-PCR and electron microscopy performed on infected cell cultures. Infected SSN-1 cell cultures developed extensive CPE, both following inoculation with the primary infective material and with supernatants passaged several times. The size and intracellular location of viral particles detected in infected cells are in agreement with that described for sea bass virus in SNN-1 cells (Frerichs et al. 1996). The ability of the cultivated virus to induce VER in Atlantic halibut larvae following bath challenge provided further evidence that the isolated virus was a fish nodavirus.

The successful cultivation of nodavirus from Atlantic halibut and the development of CPE in infected cultures at $20^{\circ} \mathrm{C}$ differ from the results of a recent report on the cultivation of nodaviruses from various marine fish species (Iwamoto et al. 1999). The authors described the extent and mode of development of CPE in SSN-1 cells inoculated with fish nodaviruses in relationship to the genotype of the infecting virus. Phylogenetic studies of the coat protein gene have been used to classify fish nodaviruses into 4 genotypes (Nishizawa et al. 1997). Iwamoto et al. (1999) showed that nodaviruses belonging to the genotype group that includes Atlantic halibut nodavirus (strain AHNor96) and BFNNV do not grow at $25^{\circ} \mathrm{C}$ while some evidence for viral growth at $20^{\circ} \mathrm{C}$ could be demonstrated. The development of CPE was not consistently observed for this group (Iwamoto et al. 1999). For the AHNor96 virus, $\mathrm{CPE}$ were not detected after $2 \mathrm{wk}$ of incubation at $20^{\circ} \mathrm{C}$ and intracellular virus particles were not demonstrated, indicating a relatively slow viral replication. The nodavirus isolated in the present study, designated AHNV 692/9/98 is closely related to AHNor96, as sequence analysis of the obtained product from RTPCR performed on infected SSN-1 cells showed 97\% homology with the corresponding segment of BFNNV. This close relationship suggests that the mode of infection in SSN-1 cells could not be ascribed to genomic differences of the nodaviruses. Other factors such as variations in virus dose during inoculation, inherent variability of the SSN-1 cells due to persistent infection by C-type retrovirus (Frerichs et al. 1991), and variations in cell culturing procedures should be considered as possible explanations for the different behaviour of the 2 Atlantic halibut isolates in SSN-1 cells. In the present study, cultivation of Atlantic halibut nodavirus at $25^{\circ} \mathrm{C}$ was not performed. It is difficult to determine whether temperatures below $20^{\circ} \mathrm{C}$ are optimal for viral growth because the SSN-1 cells grow poorly at temperatures below $20^{\circ} \mathrm{C}$.

Re-isolation of virus from challenged fish sampled $13 \mathrm{~d}$ after virus exposure was obtained with develop- 
ment of extensive CPE in the SSN-1 cell line. Virus was, however, also isolated from larvae exposed to virus for only a $4 \mathrm{~h}$ period, though a delayed development of CPE was observed in this case. These observations indicate that viral particles may have been absorbed to the surface of the larvae, or that, in spite of extensive washing of the larvae before preparation, viral particles were still present in the washing solution.

A recent study has demonstrated that Atlantic halibut larvae developed VER following water-borne challenge with infective tissue homogenate (Grotmol et al. 1999). In that study, the onset of mortality was approximately $3 \mathrm{wk}$ after challenge, and detection of nodavirus by immunohistochemistry was observed at Day 18. In the present study, using rearing conditions similar to Grotmol et al. (1999), mortality occurred much earlier (Day 6) and nodavirus antigen was detected in nervous tissue at Day 9 following challenge with cultivated virus. The observed differences in time course of disease development may be ascribed to differences in virus dose used or to the different age of the larvae at challenge. In the present study, the larvae were challenged at Day 4 after hatching, but in the study of Grotmol et al. (1999) newly hatched larvae were used.

The Atlantic halibut nodavirus retained infectivity even after 4 passages in cell culture. Péducasse et al. (1999) obtained similar results in infection experiments with sea bass nodavirus. In Norway, nodavirus-like particles have been observed in species other than Atlantic halibut, such as in the nervous tissue of turbot Scophthalmus maximus larvae (Bloch et al. 1991) and in the heart tissue of Atlantic salmon Salmo salar (Grotmol et al. 1997b, Aspehaug et al. 1999). The question whether these or other teleost species are susceptible to the Atlantic halibut nodavirus should be investigated by transmission experiments. The availability of cultivated virus will improve the feasibility and repeatability of such experiments.

Acknowledgements. The authors are grateful to Dr Magne Hansen for providing samples and information about the disease outbreak. The skilled techincal assistance of Randi Terland and Else Engeland is greatly acknowledged. We thank Dr Trine Ranheim for critical reading of the manuscript.

\section{LITERATURE CITED}

Aspehaug V, Devold M, Nylund A (1999) The phylogenetic relationship of nervous necrosis virus from halibut (Hippoglossus hippoglossus). Bull Eur Assoc Fish Pathol 19: 196-202

Editorial responsibility: Jo-Ann Leong,

Corvallis, Oregon, USA
Biering E, Nilsen F, Rødseth OM, Glette J (1994) Susceptibility of Atlantic halibut Hippoglossus hippoglossus to infectious pancreatic necrosis virus. Dis Aquat Org 20:183-190

Bloch B, Gravningen K, Larsen JL (1991) Encephalomyelitis among turbot associated with a picornavirus-like agent. Dis Aquat Org 10:65-70

Frerichs GN, Morgan D, Hart D, Skerrow C, Roberts RJ, Onions DE (1991) Spontaneously productive C-type retrovirus infection of fish cell lines. J Gen Virol 72:2537-2539

Frerichs GN, Rodger HD, Peric Z (1996) Cell culture isolation of piscine neuropathy nodavirus from juvenile sea bass, Dicentrarchus labrax. J Gen Virol 77:2067-2071

Grotmol S, Totland GK, Kvellestad A, Fjell K, Olsen AB (1995) Mass mortality of larval and juvenile hatchery-reared halibut (Hippoglossus hippoglossus L.) associated with the presence of virus-like particles in vacuolated lesions in the central nervous system and retina. Bull Eur Assoc Fish Pathol 15:176-180

Grotmol S, Totland GK, Thorud K, Hjeltnes BK (1997a) Vacuolating encephalopathy and retinopathy associated with a nodavirus-like agent: a probable cause of mass mortality of cultured larval and juvenile Atlantic halibut Hippoglossus hippoglossus. Dis Aquat Org 29:85-97

Grotmol S, Totland GK, Kryvi H (1997b) Detection of a nodavirus-like agent in heart tissue from reared Atlantic salmon Salmo salar suffering from cardiac myopathy syndrome (CMS). Dis Aquat Org 29:79-84

Grotmol S, Bergh Ø, Totland GK (1999) Transmission of viral encephalopathy and retinopathy (VER) to yolk-sac larvae of the Atlantic halibut Hippoglossus Hippoglossus: occurrence of nodavirus in various organs and a possible route of infection. Dis Aquat Org 36:95-106

Iwamoto T, Mori K, Arimoto M, Nakai T (1999) High permissivity of the fish cell line SSN-1 for piscine nodaviruses. Dis Aquat Org 39:37-47

Kärber G (1931) Beitrag zur kollektiven Behandlung pharmakologischer Reihenversuche. Arch Exp Pathol Pharmakol 162:480-483

Mori K, Nakai T, Muroga K, Arimoto M, Mushiake K, Furusawa I (1992) Properties of a new virus belonging to Nodaviridae found in larval striped jack (Pseudocaranx dentex) with nervous necrosis. Virology 187:368-371

Munday BL, Nakai T (1997) Nodaviruses as pathogens in larval and juvenile marine finfish. World J Microbiol Biotechnol 13:375-381

Nishizawa T, Mori K, Nakai T, Furusawa I, Muroga K (1994) Polymerase chain reaction (PCR) amplification of RNA of striped jack nervous necrosis virus (SJNNV). Dis Aquat Org 18:103-107

Nishizawa T, Mori K, Furuhashi M, Nakai T, Furusawa I, Muroga K (1995) Comparison of the coat protein genes of five fish nodaviruses, the causative agents of viral nervous necrosis in marine fish. J Gen Virol 76:1563-1569

Nishizawa T, Furuhashi M, Nagai T, Nakai T, Muroga K (1997) Genomic classification of fish nodaviruses by molecular phylogenetic analysis of the coat protein gene. Appl Environ Microbiol 63:1633-1636

Office International des Epizooties (OIE) (1995) Viral encephalopathy and retinopathy. In: OIE (ed) Diagnostic manual for aquatic animal diseases. OIE, Paris, p 85-90

Péducasse S, Castric J, Thiery R, Jeffroy J, Le Ven A, Baudin Laurencin F (1999) Comparative study of viral encephalopathy and retinopathy in juvenile sea bass Dicentrarchus labrax infected in different ways. Dis Aquat Org 36:11-20

Submitted: April 15, 2000; Accepted: September 28, 2000

Proofs received from author(s): November 27, 2000 